\title{
RESEARCH
}

Open Access

\section{Prevalence and associated factors for alcohol use disorder among tuberculosis patients: a systematic review and meta- analysis study}

Mogesie Necho $^{1^{*}}$ D, Mekonnen Tsehay ${ }^{1}$, Muhammed Seid ${ }^{1}$, Yosef Zenebe ${ }^{1}$, Asmare Belete ${ }^{1}$, Habitam Gelaye ${ }^{1}$ and Amare Muche ${ }^{2}$

\begin{abstract}
Background: Alcohol use disorders (AUD) in tuberculosis patients are complicated with poor compliance to antituberculosis treatment and poor tuberculosis treatment outcomes. However, aggregate data concerning this problem is not available. Therefore, this review aimed to fill the above gap by generating an average prevalence of AUD in tuberculosis patients.

Method: Our electronic search for original articles was conducted in the databases of Scopus, PubMed, and EMBASE, African Index Medicus, and psych-info. Besides, the reference list of selected articles was looked at manually to have further eligible articles for the prevalence and associated factors of AUD in tuberculosis patients. The random-effects model was employed during the analysis. MS-Excel was used to extract data and stata-11 to determine the average prevalence of AUD among tuberculosis patients. A sub-group analysis and sensitivity analysis were also run. A visual inspection of the funnel plots and an Eggers publication bias plot test were checked for the presence of publication bias.
\end{abstract}

(Continued on next page)

\footnotetext{
* Correspondence: nechomoges2014@gmail.com

${ }^{1}$ College of Medicine and Health Sciences, Department of Psychiatry, Wollo University, Dessie, Ethiopia

Full list of author information is available at the end of the article
}

C C The Author(s). 2021 Open Access This article is licensed under a Creative Commons Attribution 4.0 International License, which permits use, sharing, adaptation, distribution and reproduction in any medium or format, as long as you give appropriate credit to the original author(s) and the source, provide a link to the Creative Commons licence, and indicate if changes were made. The images or other third party material in this article are included in the article's Creative Commons licence, unless indicated otherwise in a credit line to the material. If material is not included in the article's Creative Commons licence and your intended use is not permitted by statutory regulation or exceeds the permitted use, you will need to obtain permission directly from the copyright holder. To view a copy of this licence, visit http://creativecommons.org/licenses/by/4.0/ The Creative Commons Public Domain Dedication waiver (http://creativecommons.org/publicdomain/zero/1.0/) applies to the data made available in this article, unless otherwise stated in a credit line to the data. 
(Continued from previous page)

Result: A search of the electronic and manual system resulted in 1970 articles. After removing duplicates and unoriginal articles, only 28 articles that studied 30,854 tuberculosis patients met the inclusion criteria. The average estimated prevalence of AUD in tuberculosis patients was 30\% (95\% Cl: 24.00, 35.00). This was with a slight heterogeneity $\left(1^{2}=57 \%, p\right.$-value $\left.<0.001\right)$. The prevalence of AUD in tuberculosis patients was higher in Asia and Europe; 37\% than the prevalence in the US and Africa; 24\%. Besides, the average prevalence of AUD was 39, 30, 30, and 20\% in studies with case-control, cohort, cross-sectional and experimental in design respectively. Also, the prevalence of AUD was higher in studies with the assessment tool not reported (36\%) than studies assessed with AUDIT. AUD was also relatively higher in studies with a mean age of $\geq 40$ years (42\%) than studies with a mean age $<40$ years (24\%) and mean age not reported (27\%). Based on a qualitative review; the male gender, older age, being single, unemployment, low level of education and income from socio-demographic variables, retreatment and treatment failure patients, stigma, and medication non-adherence from clinical variables were among the associated factors for AUD.

Conclusion: This review obtained a high average prevalence of AUD in tuberculosis patients and this varies across continents, design of studies, mean age of the participants, and assessment tool used. This implied the need for early screening and management of AUD in tuberculosis patients.

Keywords: Alcohol use disorder, Tuberculosis, Africa, Systematic review, Meta-analysis

\section{Background}

Tuberculosis (TB) [1] is a major public health problem in the world. TB is caused by bacteria (Mycobacterium tuberculosis) [2] and it most often affects the lungs. TB is spread through the air when people with lung TB cough, sneeze or spit. A person needs to inhale only a few germs to become infected. Despite being a preventable and curable disease, it the world's top infectious killer that 1.5 million people die from TB each year [3]. Although there are numerous global efforts to control tuberculosis (TB), it remains a chronic infectious disease with high morbidity and mortality in several parts of the world [3-5].

Several studies carried out in the world have shown alcohol use disorder as a risk factor for tuberculosis mortality, factor for default in $\mathrm{TB}$, and reason for noncompliance [6]. Alcohol is a toxic and psychoactive substance. Diagnostic and statistical manual of mental disorders, 5th edition, defines Alcohol use disorder as a problematic pattern of alcohol use leading to clinically significant impairment or distress as manifested by at least 2 symptoms criteria over the same 12-month period [7]. Based on ICD 10 criteria Alcohol use disorders is for alcohol dependence and harmful use (F10.1 and F 10.2), excluding cases with a comorbid depressive episode [8].

Alcohol consumption contributes to 3 million deaths each year globally as well as the leading risk factor for premature mortality and disability among those aged 15 to 49 years. Overall, the harmful use of alcohol is responsible for $5.1 \%$ of the global burden of disease $[9,10]$.

There are different rates of prevalence of alcohol use disorder among TB patients across developed and developing countries. For example, a study in the United
States reported that the 1-year prevalence of AUD in tuberculosis patients was $24.7 \%$ [11]. Similarly, in India, the 1-year prevalence of AUD among TB patients was $29 \%$ [12]. In Africa too, the 1-year prevalence of alcohol use disorder among tuberculosis patients was found to be $34.7 \%$ in Zambia [13], 23.2\% in South Africa [14], and $35.1 \%$ in Botswana [15].

There have been numerous publications describing, the impact of alcohol use disorders among $\mathrm{TB}$ patients [12, 16-18]. Studies show, the risk of active tuberculosis, re-infection of $\mathrm{TB}$, and $\mathrm{TB}$ treatment non-adherence is substantially increased in people who have an alcohol use disorder. The possible reason commonly reported was an influence on the immune system of alcohol itself and of alcohol-related conditions [16, 19, 20].

Alcohol use disorder has also may result in an increased chance of liver damage among TB patients and alter the metabolism of antibacterial drugs [21]. In a review done in Russia, alcohol consumption during treatment was a significant predictor of poor treatment outcomes which lead to MDR-TB [22]. Alcohol use disorders influence not only the incidence of tuberculosis but also its clinical evolution and outcome, a metaanalysis review on the impact of alcohol use on tuberculosis treatment outcomes, show it increased the risk of poor treatment outcomes in both drug-susceptible and MDR-TB patients [23].

The most commonly reported associated factors of alcohol use in TB patients include, male gender older age, Poor perceived health status, tobacco use, psychological distress, being a TB retreatment patient, among women lower education, and tobacco use [12, 14, 24, 25].

Even though a wide range of studies showed AUD as significant public health importance, there is no 
systematic review and meta-analysis conducted to assess the prevalence of AUD among TB patients. Therefore, this systematic review and meta-analysis aimed to summarize the existing evidence on the prevalence of AUD among TB patients and to formulate possible suggestions for future clinical practice and research community.

\section{Methods}

\section{Search process}

We conducted this systematic review and meta-analysis on studies that examined alcohol use disorder and associated factors in tuberculosis patients who are on antituberculosis treatment. In doing this research, the preferred reporting items for systematic reviews and metaanalyses guideline [26] have been followed. A comprehensive search of available literature was done in the databases of Embase, Scopus, PubMed, Psych-info, and African Index Medicus to recruit original research articles published between September 2007 and October 2020 (Supplementary file 1). Non-indexed articles from Google scholar, WHO websites, other institutional repositories, and manually searched reference lists of included studies were also part of the review.

\section{Eligibility criteria}

Original quantitative studies that examined the alcohol use disorder and associated factors in tuberculosis patients on anti-tuberculosis treatment were included. The studies included were randomized controlled trials, cohort, case-control, and cross-sectional in design. Studies were not eligible for inclusion if they: 1) Published in a language other than English; 2) were conducted in nonhuman subjects 3) did not assess alcohol use disorder in tuberculosis patients with a validated assessment instrument; 4) were not concerned with the exposure (tuberculosis) and outcome (alcohol use disorder) of the review. Two of the review authors (M.T and A.B) independently conducted the search process. A three-stage screening of the searched data was performed. At the initial stage, the authors screened the titles of the articles. In the second stage, the abstract of articles included in the first stage was done. In the final stage, the full paper of an article was done to assess the eligible articles for inclusion. If two of the above-mentioned researchers had a different point of view on whether or not to include an article, the senior research author (M.N.) was referred to make the final judgment.

\section{Data extraction and appraisal of study quality}

We extracted data on Microsoft-excel from the included studies using a standard data extraction template. The template consisted of the author, publication year, population and phases of treatment (Tuberculosis or MDR-
TB patients at DOT/continuation phase of treatment), socio-demographic characteristics (review population, sex, and age), region, the tool used, and prevalence of alcohol use disorder. The quality of studies included in the final analysis was evaluated with the Johanna Briggs Institute (JBI) quality assessment checklist [27-29]. The components of the JBI quality assessment checklist includes; appropriateness in the description of review subjects and setting, adequacy of the sample size, the appropriateness of sample frame, sampling procedure of participants, appropriateness of data analysis, usage of valid measurement, and reliability of measurement, adequacy of the response rate, adequate follow up time, complete follow-up, appropriate strategies to address lose to follow up and the use of appropriate statistical methods.

\section{Statistical analysis}

The pooled estimated prevalence of alcohol use disorder in tuberculosis patients was done with the Stata-11 Meta-prop package [30]. Besides, all statistical operations including funnel and forest plots were done using the stata-11 software and random effect model. We employed the Higgs $I^{2}$ statistics [31] to identify the presence of potential heterogeneity between the included studies. A Higgs $I^{2}$ value of $50 \%$ and above during the analysis was interpreted as a significant heterogeneity [31]. As heterogeneity was a main problem of the present review, a sub-group analysis was done to detect the source of this heterogeneity. Moreover, a single review leaves out at a time sensitivity analysis was also done to identify a single review that out weighted the overall result. Eyeball test [32] and the Eggers test for publication bias were implemented to identify the existence of a small review effect. All statistical values with a $P$-value $<0.05$ were interpreted as a significant value.

\section{Results \\ Search result}

Our electronic and manual search for eligible articles resulted in the identification of 1970 articles. From these records, 46 articles were duplicate articles and therefore removed in the initial stage. From the remaining 1924 articles, only 66 were obtained eligible for a full-text revision after the remaining were excluded at the different steps of screening. In the end, only 28 research articles were found to be eligible and included in the analysis (Fig. 1).

\section{Characteristics of studies included}

A total of 28 studies [11-13,15, 17, 25, 33-54] that studied our outcome of interest; alcohol use disorder (AUD) in thirty thousand eight hundred fifty-four (30854) tuberculosis patients on treatment with anti- 


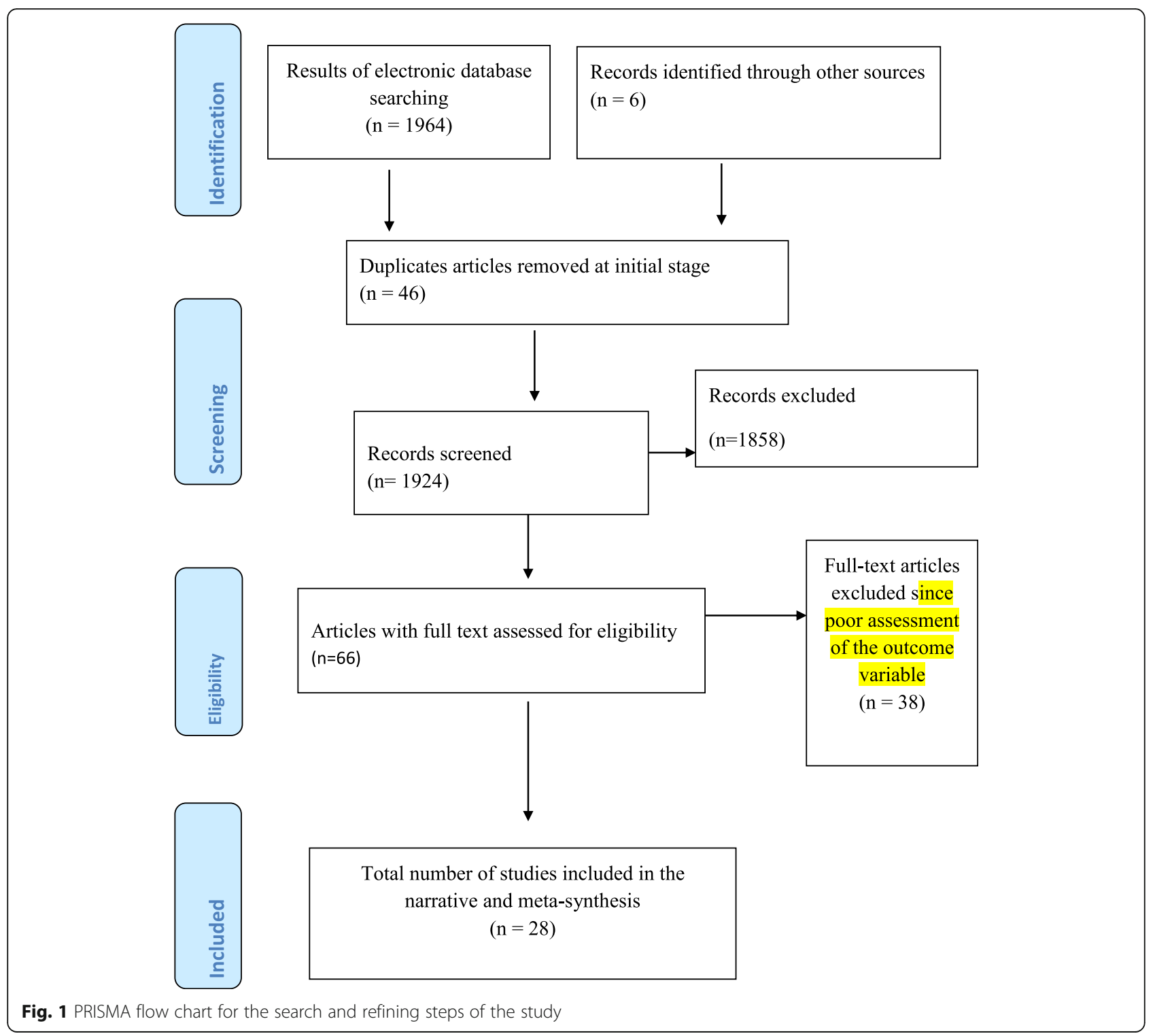

tuberculosis medications were included in the present review. Considering the regional setting where the included studies were done; six [17, 25, 35, 37, 38, 47], five $[40,45,46,48,49]$ and another five studies were from Russia, South Africa [33, 34, 50, 51, 53] and Ethiopia $[33,34,50,51,53]$ respectively. The remaining studies were from United States (US) [11, 36], Estonia [41, 42], India [12, 43, 52, 54], Thailand [44], Nigeria [39], Botswana [15], and Zambia [13]. Most of the studies in the present analysis were Cohort $[25,35,38,40,44,46$, $48,51-53]$ and cross-sectional [12, 13, 17, 33, 34, 36, 37, $41,43,45,49,50]$.

One -third of the studies included [11, 12, 15, 17, 25, 34, 44-49, 51-53] used the Alcohol use disorder identification test (AUDIT) to measure alcohol use disorder in tuberculosis patients. Besides two studies [13, 39] measured AUD with mini-international neuropsychiatric-interview(MINI), one [33] with alcohol, smoking, and substance involvement screening test(ASSIST), and another one used DSM-IV [37]. However, eight of the studies [35, 36, 38, 40-43, 50] did not report the assessment tool for the measurement of AUD. Regarding the setting of anti-tuberculosis treatment, seven $[13,17,33,45,46,48,49], 13[11,12,25,35,38-41$, $43,44,47,52]$ and another seven $[34,36,42,50,51,53]$ of the included studies involved subjects with treatment setting at the primary health care setting (PHCU), hospital and both hospital and PHCU respectively. Also, 20 [11, 12, 33, $35,37,38,43-46,49,51-53]$, four [17, 25, 42, 47] and three $[34,36,50]$ of the studies involved participant patients at the directly observed treatment(DOT), continuation and both phases of ant-tuberculosis treatment in the respective order (Table 1). 


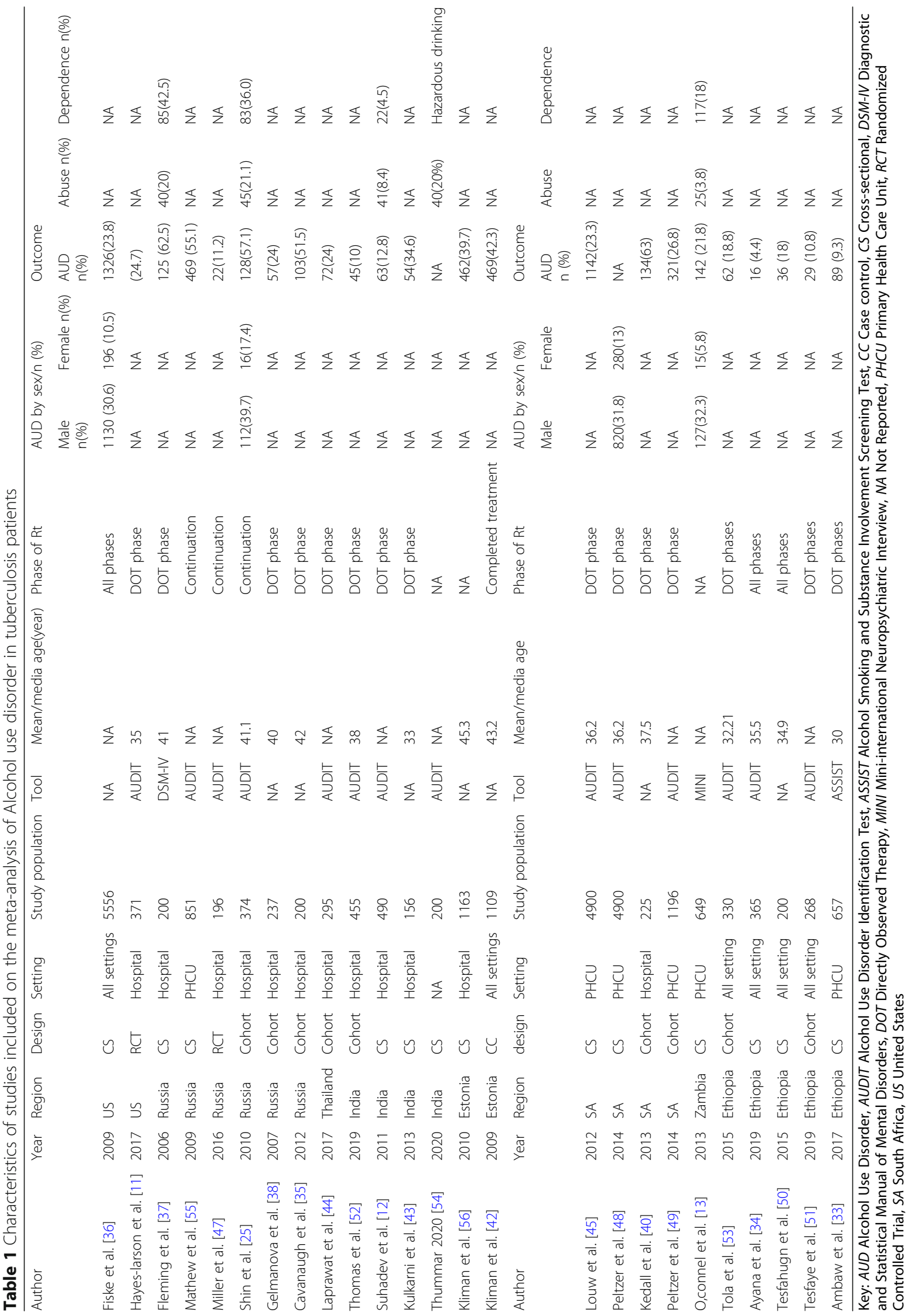


The 1-year prevalence of alcohol use disorder among tuberculosis patients

Twenty-seven studies $[11-13,15,17,25,33-53]$ had reported the prevalence of alcohol use disorder among tuberculosis patients. The reported prevalence of alcohol use disorder among tuberculosis patients among studies included in this review ranges from $4.4 \%$ in a review from Ethiopia [34] to 63\% in Russia [37] and South Africa [40]. The average prevalence of alcohol use disorder among tuberculosis patients using the random effect model was found to be $30 \%$ (95\% CI: $24.00,35.00$ ). This average prevalence of AUD was with a slight heterogeneity $\left(\mathrm{I}^{2}=57 \%, p\right.$-value $\left.<0.001\right)$ from the difference between the 27 studies (Fig. 2).

\section{The relationship between gender and AUD}

Four of the included studies [13, 25, 36, 48] have reported the prevalence of AUD in line with the sex of the participants. The average prevalence of AUD in male participants as reported by the above studies was $33.6 \%$ (95\% CI: 30.65, 36.55\%) and this was higher than the average prevalence of AUD in females 11.67\% (95\% CI: $7.81,15.54 \%)$.

\section{Subgroup analysis of the 1-year prevalence of alcohol use disorder among tuberculosis patients}

A subgroup analysis was done considering the mean age of review participants, the continent at which the review was done, study design, and assessment tool used. The average prevalence of alcohol use disorder in tuberculosis patients was higher in Asia and Europe;37\% [11, 12, $17,25,35-38,41-44,47,52]$ than the prevalence in US; $24 \%[11,36]$ and Africa; $24 \%[13,15,33,34,39,40,45$, 46, 48-51, 53] (Fig. 3). The average prevalence of AUD was $36 \%$ in studies that do not report the assessment tool for AUD [35, 36, 38, 40-43, 50] which is higher than the prevalence in studies that utilized AUDIT (26\%) [11, 12, 15, 17, 25, 34, 44-49, 51-53] (Fig. 4). Besides, studies which were case-control $[15,39,41]$ provided higher prevalence of AUD (39\%) than crosssectional $[12,13,17,33,34,36,37,41,43,45,49$, $50](30 \%)$, cohort $[25,35,38,40,44,46,48,51-53](30 \%)$ and RCT studies [11, 47] (20\%). Last but not least the average prevalence of AUD was $42 \%$ in studies with a mean age of the participants 40 years and above higher than the average prevalence of AUD in participants with a mean age of $<40$ years $(24 \%)$ and mean age not reported (27\%) (Table 2).

\section{Sensitivity analysis}

We further investigated the source of heterogeneity by doing a leave-one-out sensitivity analysis to identify whether individual studies out weighted the average prevalence of AUD. Our result revealed that the average prevalence of AUD obtained when each study was omitted at a time from the analysis ranges between $28 \%$ $(23.00,35.00)$ and $31 \%(25.00,36.00)$. This implied that the average prevalence of AUD among tuberculosis patients was not out weighted by a single review (Table 3 ).

\section{Publication Bias}

The Egger's publication bias plot is near the origin and Egger's tests $p$-value was $(P=0.58)$ showing the absence of publication bias for the prevalence of AUD among tuberculosis patients. This was also supported by asymmetrical distribution on the funnel plot for a logit event rate of prevalence of AUD in tuberculosis patients against its standard error (Fig. 5).

\section{Factors associated with alcohol use disorder among tuberculosis patients}

Among 28 studies [11-13, 15, 17, 25, 33-53] included in the present meta-analysis, only eight $[11-13,25$, $36,37,44,48$ ] reported the associated factors for alcohol use disorder among tuberculosis patients. Our qualitative synthesis for the socio-demographic factors associated with AUD in tuberculosis patients revealed that male gender $[11,12,25,36,48]$, age older than 35 years [12], being single, divorced or widowed [12, 13], being unemployed [13], being black American [36], colored ethnicity [48], low level of education $[12,48]$, no educational background [11], low level of income (<70US\$ per month) [12] and poverty [48]. Besides, being on category-II tuberculosis treatmen$\mathrm{t}$ (relapse and treatment failure) [12], TB retreatment patient status and non-adherence to anti-TB medication [48], patients with chronic/relapsing form of tuberculosis [37], patients with perceived TB stigma [11], patients who feel ashamed of having TB [11], people close to you would avoid you because of TB [11], HIV-co-infection and low HIV CD4-count [11], having cavitary lesions on chest radiographic examination [36], and smear-positive and culture-positive types of TB [36] were also the reported clinical and tuberculosis related factors for AUD (Table 4).

\section{Discussion}

Alcohol use disorder in individuals with tuberculosis is an important driver for poor tuberculosis treatment outcomes [16]. In comparison to tuberculosis patients with no alcohol use disorder, those who have this problem are faced higher rates of treatment failure, relapse, and death. Despite this and other impacts that AUD poses on individuals with tuberculosis, to the knowledge of researchers of the present review; there is no aggregate evidence on the average prevalence of AUD among this target population. The present meta-analysis study, therefore, intended to narrow the gap in evidence in this 


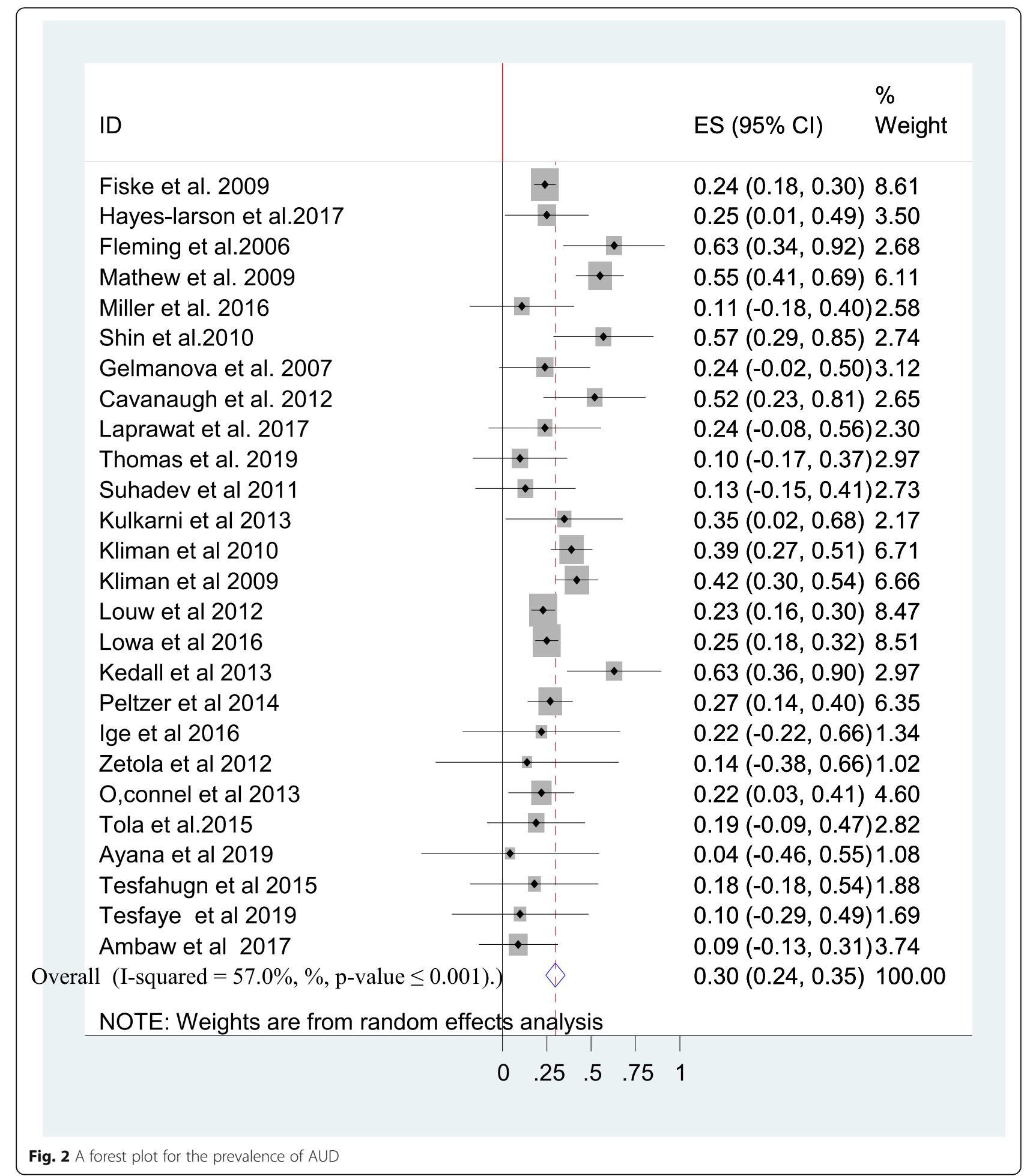

area by supplementing solid evidence on the 1-year prevalence of alcohol use disorder and its associated factors in TB patients. The evidence obtained will be of paramount importance for public health practitioners and policymakers.
Therefore it was necessary to have an average estimate for the prevalence of AUD in the global context and the current meta-analysis was therefore rooted in this justification. The average prevalence of alcohol use disorder among tuberculosis patients using the random effect 


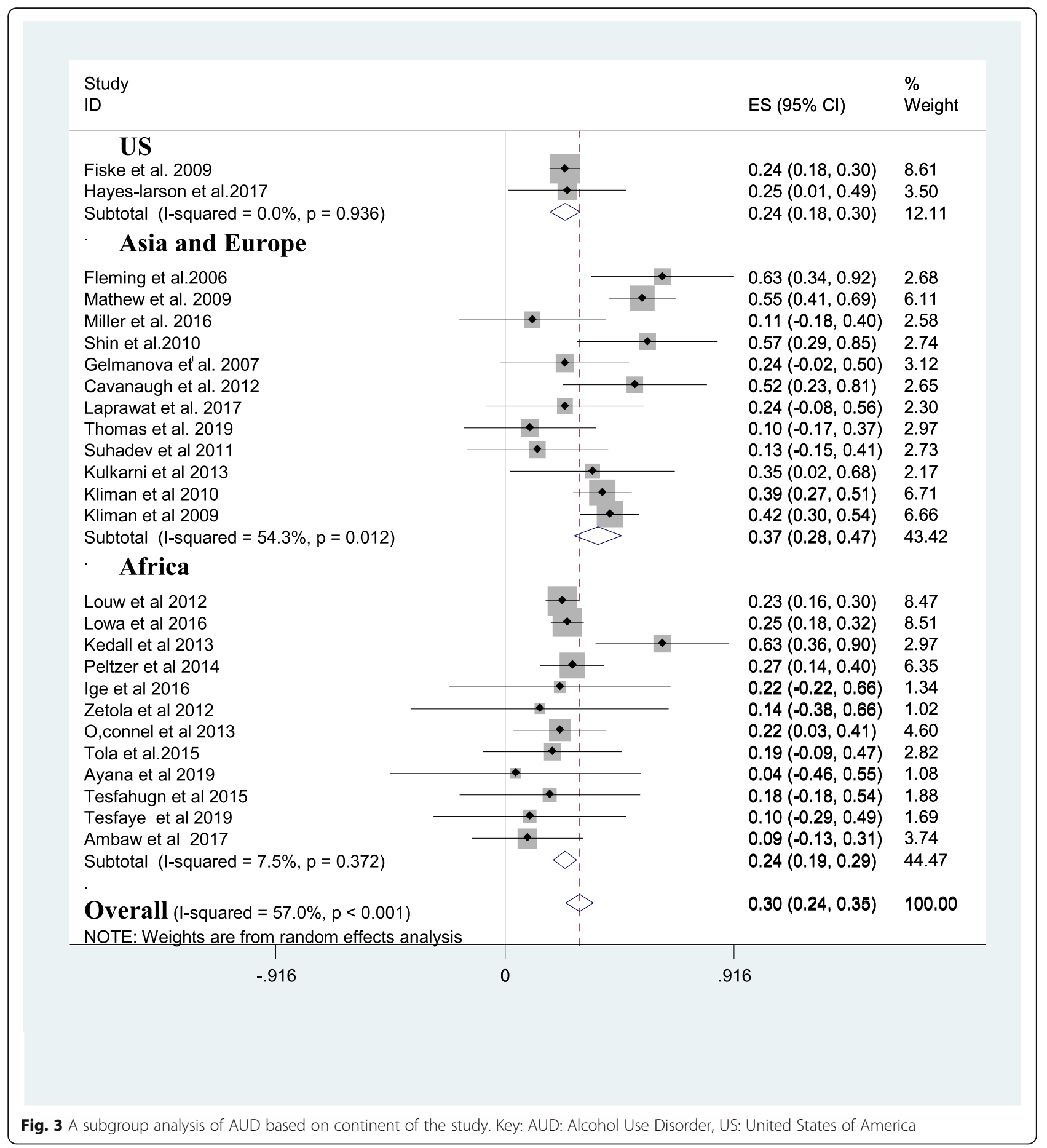

model was found to be $30 \%$ (95\% CI: $24.00,35.00$ ). This result was consistent with the global average prevalence of AUD among individuals living with HIV/AIDS (29.80\%) [57].

However, the present finding was higher when compared with the average prevalence of AUD in individuals living with HIV/AIDS in Africa (22\%) [58]. It was also higher than the DSM-V 12 month prevalence of alcohol use disorder in the adult general population in the USA (13.9\%) [59]. Moreover, the finding was higher than the average prevalence of AUD in the European, Australian, and Ethiopian general population in which the AUD prevalence was $11.1 \%$ [60], $11.8 \%$ [61], and $23.86 \%$ [62]. This could be the use of alcohol as a coping response for the psychological distress associated with the perceived severity of such life-threatening illness $[60,61]$. 
Study

ID

\author{
$\%$ \\ ES $(95 \% \mathrm{Cl}) \quad$ Weight
}

\section{Not reported \\ Fiske et al. 2009 \\ Gelmanova et al. 2007 \\ Cavanaugh et al. 2012 \\ Kulkarni et al 2013 \\ Kliman et al 2010 \\ Kliman et al 2009 \\ Kedall et al 2013 \\ Tesfahugn et al 2015 \\ Subtotal $(\mathrm{I}$-squared $=62.0 \%, \mathrm{p}=0.01$ )}

\section{AUDIT}

Hayes-larson et al.2017

Mathew et al. 2009

Miller et al. 2016

Shin et al.2010

Laprawat et al. 2017

Thomas et al. 2019

Suhadev et al 2011

Louw et al 2012

Lowa et al 2016

Peltzer et al 2014

Zetola et al 2012

Tola et al.2015

Ayana et al 2019

Tesfaye et al 2019

Subtotal $(\mathrm{I}$-squared $=54.0 \%, p=0.008)$

\section{MINI, DSM-IV\&ASSIST}

Fleming et al.2006

lge et al 2016

O,connel et al 2013

Ambaw et al 2017

Subtotal $(\mathrm{I}$-squared $=66.1 \%, p=0.031)$

Overall (I-squared $=57.0 \%, p<0.001$ )

NOTE: Weights are from random effects analysis

$$
-.916
$$

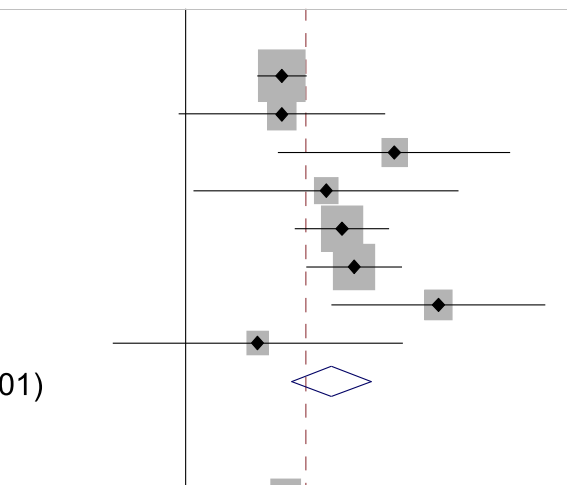

$0.24(0.18,0.30) \quad 8.61$

$0.24(-0.02,0.50) 3.12$

$0.52(0.23,0.81) \quad 2.65$

$0.35(0.02,0.68) \quad 2.17$

$0.39(0.27,0.51) \quad 6.71$

$0.42(0.30,0.54) \quad 6.66$

$0.63(0.36,0.90) 2.97$

$0.18(-0.18,0.54) 1.88$

$0.36(0.26,0.46) \quad 34.77$

$0.25(0.01,0.49) \quad 3.50$

$0.55(0.41,0.69) \quad 6.11$

$0.11(-0.18,0.40) 2.58$

$0.57(0.29,0.85) \quad 2.74$

$0.24(-0.08,0.56) 2.30$

$0.10(-0.17,0.37) 2.97$

$0.13(-0.15,0.41) 2.73$

$0.23(0.16,0.30) \quad 8.47$

$0.25(0.18,0.32) \quad 8.51$

$0.27(0.14,0.40) \quad 6.35$

$0.14(-0.38,0.66) 1.02$

$0.19(-0.09,0.47) 2.82$

$0.04(-0.46,0.55) 1.08$

$0.10(-0.29,0.49) 1.69$

$0.26(0.19,0.34) \quad 52.88$
$0.63(0.34,0.92) \quad 2.68$

$0.22(-0.22,0.66) 1.34$

$0.22(0.03,0.41) \quad 4.60$

$0.09(-0.13,0.31) 3.74$

$0.28(0.06,0.51) \quad 12.35$

$0.30(0.24,0.35) \quad 100.00$

Fig. 4 A subgroup analysis of alcohol use disorder based on measurement tools. Key: AUDIT: Alcohol Use Disorder Identification Test, ASSIST: Alcohol Smoking and Substance Involvement Screening Test "DSM-IV: Diagnostic and Statistical Manual of Mental Disorders, MINI: Mini-international Neuropsychiatric Interview

On the contrary, the average prevalence of AUD in the present review was lower when compared with the prevalence of AUD in mental disorders (28 to 70\%) [63]. Individuals with mental illness are most of the time in poor judgment and insight towards their illness which could be responsible for the higher prevalence of AUD.
The average 1-year prevalence of AUD in male participants as reported by a few of the studies was $33.6 \%$ and higher than the average prevalence of AUD in females (11.67\%). This was consistent with earlier studies in Canada [64], the East African countries [65], and the United Kingdom [66]. The sociocultural expectations 
Table 2 A subgroup analysis of the prealence of alcohol use disorder among tuberculosis patients

\begin{tabular}{|c|c|c|c|c|c|c|}
\hline \multirow[t]{2}{*}{ Subgroup } & & \multirow{2}{*}{$\begin{array}{l}\text { Number } \\
\text { of } \\
\text { studies }\end{array}$} & \multicolumn{2}{|l|}{ Estimates } & \multirow{2}{*}{$\begin{array}{l}\text { Heterogeneity } \\
\mathrm{I}^{2}\end{array}$} & \multirow[b]{2}{*}{$P$-value } \\
\hline & & & Prevalence & $95 \% \mathrm{Cl}$ & & \\
\hline \multirow[t]{3}{*}{ Mean age } & Not reported & 10 & 0.27 & $0.19,0.34$ & $57.3 \%$ & $P=0.012$ \\
\hline & Below 40 years age & 9 & 0.24 & $0.14,0.33$ & $35 \%$ & $P=0.135$ \\
\hline & 40 years and above & 7 & 0.42 & $0.43,0.50$ & $8.2 \%$ & $P=0.37$ \\
\hline \multirow[t]{3}{*}{ Continent } & US & 2 & 0.24 & $0.18,0.30$ & $0 \%$ & $P=0.936$ \\
\hline & Asia and Europe & 12 & 0.37 & $0.28,0.47$ & $54.3 \%$ & $P=0.012$ \\
\hline & Africa & 12 & 0.24 & $0.19,0.29$ & $7.5 \%$ & $P=0.372$ \\
\hline \multirow[t]{4}{*}{ Study design } & Cross-sectional & 11 & 0.3 & $0.21,0.39$ & $70.4 \%$ & $P \leq 0.01$ \\
\hline & Cohort & 10 & 0.3 & $0.21,0.40$ & $48 \%$ & $P \leq 0.01$ \\
\hline & Case control & 3 & 0.39 & $0.28,0.51$ & $0 \%$ & $P=0.43$ \\
\hline & $\mathrm{RCT}$ & 2 & 0.2 & $0.01,0.38$ & $0 \%$ & $P=0.47$ \\
\hline \multirow[t]{3}{*}{ Assessment tool } & AUDIT & 14 & 0.26 & $0.19,0.34$ & $54 \%$ & $P=0.008$ \\
\hline & MINI, DSM-IV\&ASSIST & 4 & 0.28 & $0.08,0.51$ & $66.1 \%$ & $P=0.0031$ \\
\hline & Not reported & 8 & 0.36 & $0.26,0.46$ & $62 \%$ & $P=0.01$ \\
\hline
\end{tabular}

Key: AUDIT Alcohol Use Disorder Identification Test, ASSIST Alcohol Smoking and Substance Involvement Screening Test, CS Cross-sectional, DSM-IV Diagnostic and Statistical Manual of Mental Disorders, MINI Mini-international Neuropsychiatric Interview, RCT Randomized Controlled Trial, US United States

Table 3 A sensitivity analysis of the prevalence of alcohol use disorder among tuberculosis patients

\begin{tabular}{|c|c|c|c|}
\hline No & Study excluded from the analysis & Average prevalence of AUD & $95 \%$ confidence interval \\
\hline 1 & Fiske et al. & 0.3 & $0.24,0.36$ \\
\hline 2 & Hayes-larson et al & 0.3 & $0.24,0.36$ \\
\hline 3 & Fleming et al & 0.29 & $0.24,0.34$ \\
\hline 4 & Mathew et al & 0.28 & $0.23,0.33$ \\
\hline 5 & Miller et al & 0.3 & $0.25,0.36$ \\
\hline 6 & Shin et al & 0.3 & $0.24,0.35$ \\
\hline 7 & Gelmanova et al & 0.3 & $0.24,0.36$ \\
\hline 8 & Cavanaugh et al & 0.29 & $0.24,0.35$ \\
\hline 9 & Laprawat et al & 0.28 & $0.25,0.31$ \\
\hline 10 & Thomas et al & 0.3 & $0.24,035$ \\
\hline 11 & Suhadev et al. & 0.3 & $0.25,0.36$ \\
\hline 12 & Kulkarni et al. & 0.3 & $0.24,035$ \\
\hline 13 & Kliman et al. & 0.29 & $0.24,035$ \\
\hline 14 & Kliman et al. & 0.29 & $0.23,0.35$ \\
\hline 15 & Louw et al & 0.3 & $0.24,0.36$ \\
\hline 16 & Lowa et al & 0.3 & $0.24,0.36$ \\
\hline 17 & Kedall et al & 0.28 & $0.25,0.31$ \\
\hline 18 & Peltzer et al & 0.3 & $0.24,0.36$ \\
\hline 19 & Ige et al. & 0.3 & $0.24,0.36$ \\
\hline 20 & Zetola et al & 0.3 & $0.25,0.36$ \\
\hline 21 & O,connel et al & 0.3 & $0.25,0.36$ \\
\hline 22 & Tola et al & 0.3 & $0.25,0.36$ \\
\hline 23 & Ayana et al & 0.3 & $0.25,0.36$ \\
\hline 24 & Tesfahugn et al & 0.3 & $0.24,0.36$ \\
\hline 25 & Tesfaye et al & 0.3 & $0.25,0.36$ \\
\hline 26 & Ambaw et al. & 0.31 & $0.25,0.36$ \\
\hline
\end{tabular}




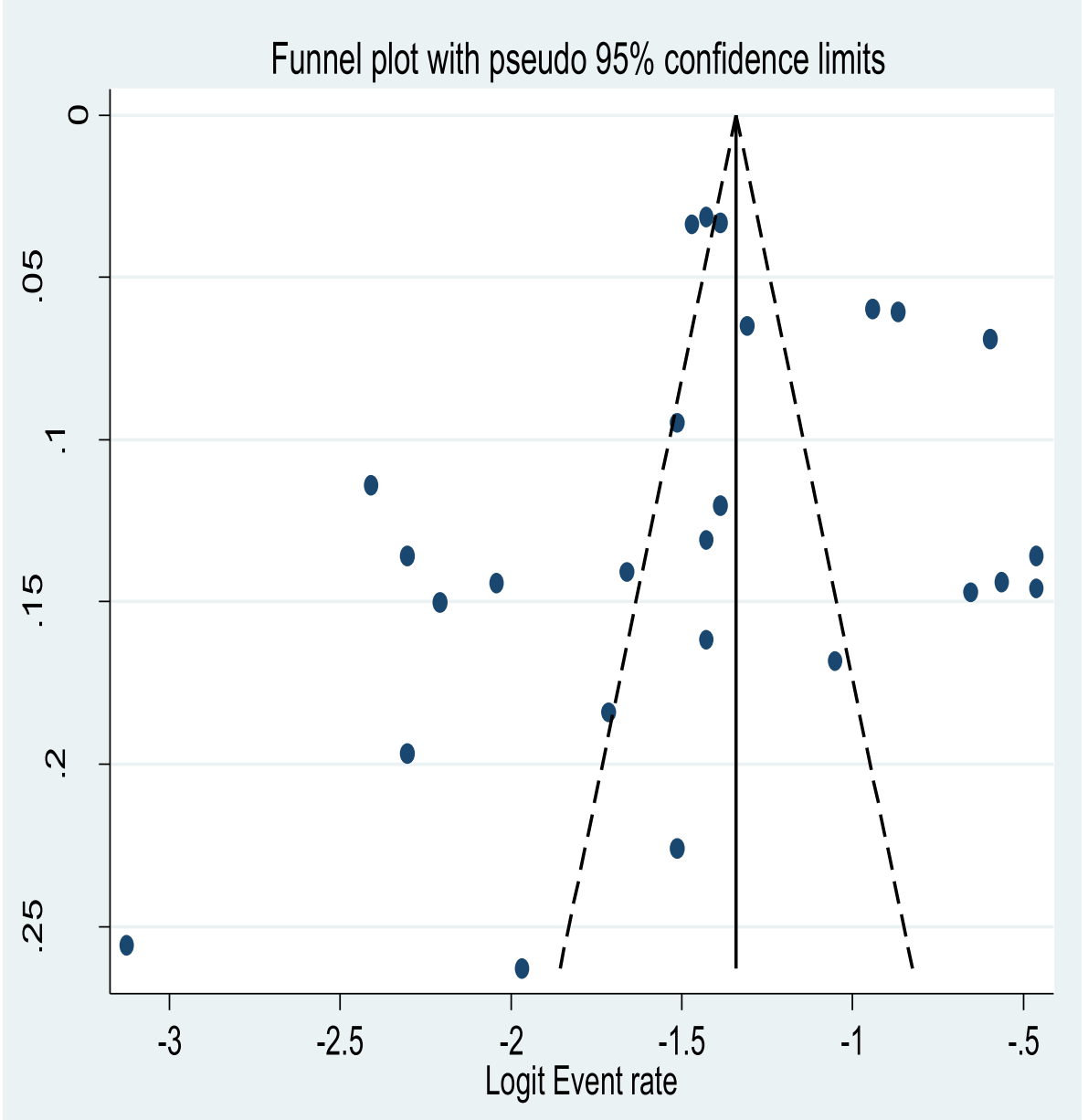

Fig. 5 A funnel plot of logit event rate against its standard error

and influences between males and females could be responsible for this. Besides, differences in the neurochemistry of the brain between men and women like the higher release of dopamine in men than women with the same amount of alcohol intake could lead to the high level of AUD in men [67]. However, the exact justification for such differences is the recommendation for future researchers.

The average prevalence of AUD was with a slight heterogeneity $\left(\mathrm{I}^{2}=57 \%, p\right.$-value $\left.<0.001\right)$ from the difference between the 27 studies. For this reason, we did a subgroup analysis. Therefore we did a subgroup analysis and the average prevalence of AUD varied based on the continent of the review, the measurement tool for AUD, the type of study design, and the mean age of the participants.

The subgroup analysis based on the continent where the review was done showed a significant difference in the average prevalence of alcohol use disorder among tuberculosis patients. The average prevalence of AUD in tuberculosis patients was higher in Asia and Europe; $37 \%[11,12,17,25,35-38,41-44,47,52]$ than the prevalence in US; $24 \%[11,36]$ and Africa; $24 \%[13,15$, $33,34,39,40,45,46,48-51,53]$. This was supported by earlier studies [68]. Differences in the cultural context, variation in the availability of alcoholic drinks, and socio-economic variants could bring the variation. Furthermore, the difference in the number of articles included in the subgroup could also be responsible.

The average prevalence of AUD was $36 \%$ in studies that do not report the assessment tool for AUD [35, 36, 38, $40-43,50]$ higher than the prevalence in studies that utilized AUDIT (26\%) [11, 12, 15, 17, 25, 34, 44-49, 51-53]. This could happen due to the possibility of inclusion of mild levels of alcohol use and the overestimation of AUD in studies that did not report the measurement tool.

Besides, case control studies $[15,39,41]$ provided higher prevalence of AUD (39\%) than cross-sectional 
Table 4 Factors that increase the risk of alcohol use disorder in tuberculosis patients

\begin{tabular}{|c|c|}
\hline Factors that increase the risk of AUD in tuberculosis patients & Factors that are protective of AUD in tuberculosis patients \\
\hline $\begin{array}{l}\text { Socio-demographic factors } \\
\text { Male gender }[11,12,25,36,48] \\
\text { Age older than } 35 \text { years }[12] \\
\text { Being single, divorced or widowed }[12,13] \\
\text { Being unemployed }[13] \\
\text { Being black American }[36] \\
\text { Coloured ethnicity }[48] \\
\text { Low level of education }[12,48] \\
\text { No educational background [1 } 1] \\
\text { Low level of income (<70US\$ per month) }[12] \text { and poverty [48] }\end{array}$ & $\begin{array}{l}\text { Socio-demographic factors } \\
41 \text { to } 54 \text { years of age }[44] \\
\text { Higher educational achievement and marital relationship }[12,44] \\
\text { Female gender }[12]\end{array}$ \\
\hline $\begin{array}{l}\text { Clinical and tuberculosis related factors } \\
\text { Being on category-II tuberculosis treatment(relapse and treatment fail- } \\
\text { ure) [12] } \\
\text { TB retreatment patient status and non-adherence to anti-TB medication } \\
\text { [48] } \\
\text { Patients with chronic/relapsing form of tuberculosis [37] } \\
\text { Patients with perceived TB stigma [11] } \\
\text { Patients who feel ashamed of having TB [11] } \\
\text { People close to you would avoid you because of TB [11] } \\
\text { HIV-co-infection and low HIV CD4-count [11] } \\
\text { Having cavitary lesions on chest radiographic examination [36] } \\
\text { Smear positive and culture positive types of TB [36] }\end{array}$ & $\begin{array}{l}\$ \text { Clinical and tuberculosis related factors } \\
\text { Tuberculosis treatment category I and III [12] } \\
\text { Having extra pulmonary TB as compared to Pulmonary of mixed type of } \\
\text { TB [36] } \\
\text { Good tuberculosis medication adherence [48] }\end{array}$ \\
\hline 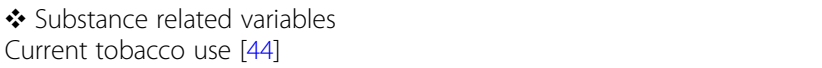 & \\
\hline
\end{tabular}

$[12,13,17,33,34,36,37,41,43,45,49,50](30 \%)$, cohort $[25,35,38,40,44,46,48,51-53](30 \%)$. The small number of studies included in the case control subgroup might affect the validity of the estimate and result in higher prevalence of AUD.

Finally, the mean age of the review participants included in the review was considered during the subgroup analysis and the average prevalence of AUD was $42 \%$ in studies with a mean age of the participants 40 years and above which is higher than the average prevalence of AUD in participants with a mean age of $<40$ years $(24 \%)$ and mean age not reported $(27 \%)$. This was however in contradiction with the study finding by grant et al. [69] in which the prevalence of AUD declines over the age of 40 years.

Regarding the factors associated with AUD, our qualitative synthesis showed that the socio-demographic factors such as male gender [11, 12, 25, 36, 48], age older than 35 years [12], being single, divorced, or widowed $[12,13]$, being unemployed [13], being black American [36], colored ethnicity [48], low level of education [12, 48], no educational background [11], low level of income (<70US\$ per month) [12] and poverty [48] were related to AUD. Also, being on category-II tuberculosis treatment(relapse and treatment failure) [12], TB retreatment patient status and non-adherence to anti-TB medication [48], patients with chronic/relapsing form of tuberculosis [37], patients with perceived TB stigma [11], patients who feel ashamed of having TB [11], people close to you would avoid you because of TB [11], HIV-co-infection and low HIV CD4-count [11], having cavitary lesions on chest radiographic examination [36], and smear-positive and culture-positive types of TB [36] were also the reported clinical and tuberculosis related factors for AUD.

\section{Difference between included studies in the meta-analysis} Due to the slight heterogeneity in the present metaanalysis; we did a subgroup analysis. The result from subgroup analysis showed that the measurement tool employed to screen AUD, the continent where the study was done, the mean age of the participants studied, and type of the study design were identified as sources of difference between the 27 included studies. Furthermore, a single study leaves out analysis was done to screen studies outweighing the overall result but the average prevalence of AUD was not outweighed by a single particular study. This review is the first of its type to assess the average prevalence of alcohol use disorder in tuberculosis patients. The use of a pre-determined search strategy to obtain eligible articles minimizes the reviewer's bias which increases the study quality. Besides, the implementation of subgroup analysis based on the measurement tool, the continent of the study, study setting, and mean age to identify the source of heterogeneity is also the strength of the present study. However, the use of a few studies in some groups of the subgroup analysis might affect the validity of estimate so that under or overestimation could occur. Moreover, the exclusion of articles published in non-English language might have 
also an effect on the magnitude of the average prevalence of AUD.

\section{Implications of this study for clinical practice, researchers, and policymakers}

First, this review revealed that clinical practitioners who work in tuberculosis treatment centers have to be conscious that AUD is a common problem in tuberculosis patients and to offer patients management or treatment. Second, the high average estimated prevalence of AUD in tuberculosis patients obtained in the review as compared to the average estimated prevalence of AUD in the general population forces researchers to raise a question of why and what factors are responsible for this. Finally, the results inform policymakers and program planners that AUD is a significant public health concern for tuberculosis patients on treatment. This mitigates for a holistic approach during the clinical management of tuberculosis patients.

In conclusion, initiation of joint TB-alcohol collaborative activities including screening of all $\mathrm{TB}$ patients for alcohol use and screening of all patients consuming alcohol for TB should be initiated.

\section{Conclusion}

The current review obtained a high average prevalence of AUD in tuberculosis patients and this prevalence varies with the measurement tool employed to screen AUD, the continent where the study was done, the mean age of the participants, and the type of the study design was. Moreover, the prevalence of AUD was higher in males than in females. Our qualitative synthesis showed that the factors such as male gender, older age, being single, being unemployed, low level of educational background, low level of income, Category-II tuberculosis treatment, $\mathrm{TB}$ retreatment patient, non-adherence to anti-TB medication, and perceived TB stigma was among also the associated factors for AUD in tuberculosis patients. Therefore early screening and management of AUD and its associated factors are essential in tuberculosis patients.

\section{Supplementary Information}

The online version contains supplementary material available at https://doi. org/10.1186/s13011-020-00335-w.

Additional file 1: Supplementary file 1. A search strategy for the study.

\section{Abbreviations}

AUD: Alcohol Use Disorder; AUDIT: Alcohol Use Disorder Identification Test; ASSIST: Alcohol Smoking and Substance Involvement Screening Test; CC: Case-control; CS: Cross-sectional; DSM-IV: Diagnostic and Statistical Manual of Mental Disorders; DOT: Directly Observed Therapy; MINI: Miniinternational Neuropsychiatric Interview; NA: Not Reported; PHCU: Primary Health Care Unit; PRISMA: Preferred Reporting Items for Systematic Reviews and Meta-analysis; RCT: Randomized Controlled Trial; SA: South Africa; US: United States; USA: United States of America

\section{Acknowledgments}

None

Authors' contributions

MN conceived and started the present review. MT and AB developed the search strategy. MN prepared the first draft of the manuscript. All authors critically reviewed and approved the last version of the manuscript.

Funding

We have no funding source for this research work.

Availability of data and materials

All data regarding this research work is included in the manuscript.

Ethics approval and consent to participate

Not applicable.

Consent for publication

Not Applicable.

\section{Competing interests}

No conflict of interest for the present review.

\section{Author details}

${ }^{1}$ College of Medicine and Health Sciences, Department of Psychiatry, Wollo University, Dessie, Ethiopia. ${ }^{2}$ College of Medicine and Health Sciences, Department of Public Health, Wollo University, Dessie, Ethiopia.

Accepted: 9 December 2020

Published online: 03 January 2021

References

1. Macintyre K, Bloss E. Alcohol brewing, and the African tuberculosis epidemic. Med Anthropol. 2011;30(2):126-35.

2. Organization WH. Global status report on alcohol and health 2018: executive summary: Geneva: World Health Organization; 2018.

3. Kyu HH, Maddison ER, Henry NJ, Ledesma JR, Wiens KE, Reiner R Jr, et al. Global, regional, and national burden of tuberculosis, 1990-2016: results from the global burden of diseases, injuries, and risk factors 2016 study. Lancet Infect Dis. 2018;18(12):1329-49.

4. Seddon JA, Shingadia D. Epidemiology and disease burden of tuberculosis in children: a global perspective. Infect Drug Resist. 2014;7.

5. Kyu HH, Maddison ER, Henry NJ, Mumford JE, Barber R, Shields C, et al. The global burden of tuberculosis: results from the global burden of disease study 2015. Lancet Infect Dis. 2018;18(3):261-84.

6. Jaggarajamma K, Sudha G, Chandrasekaran V, Nirupa C, Thomas A, Santha T, et al. Reasons for non-compliance among patients treated under revised National Tuberculosis Control Programme (RNTCP), Tiruvallur district, South India. Indian J Tuberc. 2007;54(3):130-5.

7. Association AP. Diagnostic and statistical manual of mental disorders (DSM$\left.5^{\circledR}\right)$ : USA: American Psychiatric Pub; 2013.

8. Organization $\mathrm{WH}$. The ICD-10 classification of mental and behavioral disorders: diagnostic criteria for research: Geneva: World Health Organization; 1993.

9. Organization WH. Global status report on alcohol and health 2018: Geneva: World Health Organization; 2019.

10. Organization WH. Global status report on alcohol and health 2018 (Geneva). Geneva: World Health Organization; 2018.

11. Hayes-Larson E, Hirsch-Moverman Y, Saito S, Frederix K, Pitt B, MaamaMaime $L$, et al. Depressive symptoms and hazardous/harmful alcohol use are prevalent and correlate with stigma among TB-HIV patients in Lesotho. Int J Tuberc Lung Dis. 2017;21(11):S34-41.

12. Suhadev M, Thomas BE, Murugesan P, Chandrasekaran V, Charles N, Durga $\mathrm{R}$, et al. Alcohol use disorders (AUD) among tuberculosis patients: a study from Chennai, South India. PLoS One. 2011;6(5):e19485.

13. O'Connell R, Chishinga N, Kinyanda E, Patel V, Ayles H, Weiss HA, et al. Prevalence and correlates of alcohol dependence disorder among TB and HIV infected patients in Zambia. PLoS One. 2013;8(9):e74406. 
14. Peltzer K, Louw J, Mchunu G, Naidoo P, Matseke G, Tutshana B. Hazardous and harmful alcohol use and associated factors in tuberculosis public primary care patients in South Africa. Int J Environ Res Public Health. 2012; 9(9):3245-57.

15. Zetola N, Modongo C, Kip E, Gross R, Bisson G, Collman R. Alcohol use and abuse among patients with multidrug-resistant tuberculosis in Botswana. Int J Tuberc Lung Dis. 2012;16(11):1529-34.

16. Rehm J, Samokhvalov AV, Neuman MG, Room R, Parry C, Lönnroth K, et al. The association between alcohol use, alcohol use disorders, and tuberculosis (TB). A systematic review. BMC Public Health. 2009;9(1):450.

17. Mathew TA, Yanov SA, Mazitov R, Mishustin SP, Strelis AK, Yanova GV, et al. Integration of alcohol use disorders identification and management in the tuberculosis program in Tomsk oblast, Russia. Eur J Public Health. 2009;19(1): $16-8$.

18. Jacobson JM. Alcohol use disorder and tuberculosis. Alcohol Health Res World. 1992;16(1):39-46.

19. Lönnroth K, Williams BG, Stadlin S, Jaramillo E, Dye C. Alcohol use as a risk factor for tuberculosis-a systematic review. BMC Public Health. 2008;8(1):289.

20. Shin S, Livchits V, Connery HS, Shields A, Yanov S, Yanova G, et al. Effectiveness of alcohol treatment interventions integrated into routine tuberculosis care in T Omsk. R Russia Addict. 2013;108(8):1387-96.

21. Rehm J. The risks associated with alcohol use and alcoholism. Alcohol Res Health. 2011;34(2):135.

22. Shin SS, Pasechnikov AD, Gelmanova I, Peremitin G, Strelis A, Andreev Y, et al. Treatment outcomes in an integrated civilian and prison MDR-TB treatment program in Russia. Int J Tuberc Lung Dis. 2006;10(4):402-8.

23. Ragan E, Kleinman M, Sweigart B, Gnatienko N, Parry C, Horsburgh C, et al. The impact of alcohol use on tuberculosis treatment outcomes: a systematic review and meta-analysis. Int J Tuberc Lung Dis. 2020;24(1):73-82.

24. Harling G, Ehrlich R, Myer L. The social epidemiology of tuberculosis in South Africa: a multilevel analysis. Soc Sci Med. 2008;66(2):492-505.

25. Shin SS, Mathew TA, Yanova GV, Fitzmaurice GM, Livchits V, Yanov SA, et al. Alcohol consumption among men and women with tuberculosis in Tomsk, Russia. Cent Eur J Public Health. 2010;18(3):132.

26. Moher D, Shamseer L, Clarke M, Ghersi D, Liberati A, Petticrew M, et al. Preferred reporting items for systematic review and meta-analysis protocols (PRISMA-P) 2015 statement. Systematic reviews. 2015;4(1):1.

27. Munn Z, Moola S, Lisy K, Riitano D, Tufanaru C. Methodological guidance for systematic reviews of observational epidemiological studies reporting prevalence and cumulative incidence data. Int J Evid Based Healthc. 2015; 13(3):147-53.

28. Moola S, Munn Z, Tufanaru C, Aromataris E, Sears K, Sfetcu R, et al. Chapter 7: systematic reviews of etiology and risk. In: Joanna Briggs Institute Reviewer's Manual The Joanna Briggs Institute; 2017. p. 2019-05.

29. Peters M, Godfrey C, Mclnerney P, Soares C, Khalil H, Parker D. The Joanna Briggs institute reviewers' manual 2015: a methodology for JBI scoping reviews; 2015.

30. Nyaga VN, Arbyn M, Aerts M. Metaprop: a Stata command to perform a meta-analysis of binomial data. Arch Public Health. 2014;72(1):39.

31. Higgins JP, Thompson SG. Quantifying heterogeneity in a meta-analysis. Stat Med. 2002;21(11):1539-58.

32. Liu JL. The role of the funnel plot in detecting publication and related biases in meta-analysis. Evid Based Dentist. 2011;12(4):121.

33. Ambaw F, Mayston R, Hanlon C, Alem A. Burden, and presentation of depression among newly diagnosed individuals with TB in primary care settings in Ethiopia. BMC Psychiatry. 2017;17(1):57.

34. Ayana TM, Roba KT, Mabalhin MO. Prevalence of psychological distress and associated factors among adult tuberculosis patients attending public health institutions in Dire Dawa and Harar cities, eastern Ethiopia. BMC Public Health. 2019;19(1):1392.

35. Cavanaugh J, Kazennyy B, Nguyen M, Kiryanova E, Vitek E, Khorosheva T, et al. Outcomes and follow-up of patients treated for multidrug-resistant tuberculosis in Orel, Russia, 2002-2005. Int J Tuberc Lung Dis. 2012;16(8): 1069-74.

36. Fiske CT, Hamilton CD, Stout JE. Alcohol use and clinical manifestations of tuberculosis. J Infect. 2009;58(5):395-401.

37. Fleming MF, Krupitsky E, Tsoy M, Zvartau E, Brazhenko N, Jakubowiak W, et al. Alcohol and drug use disorders, HIV status and drug resistance in a sample of Russian TB patients. Int J Tuberc Lung Dis. 2006;10(5):565-70.

38. Gelmanova I, Keshavjee S, Golubchikova V, Berezina V, Strelis AK, Yanova GV, et al. Barriers to successful tuberculosis treatment in Tomsk, Russian
Federation: non-adherence, default and the acquisition of multidrug resistance. Bull World Health Organ. 2007:85:703-11.

39. Ige $\mathrm{O}$. Suicidality in tuberculosis patients and their non-tuberculosis family contacts in Nigeria; 2016.

40. Kendall EA, Theron D, Franke MF, Van Helden P, Victor TC, Murray MB, et al. Alcohol, hospital discharge, and socioeconomic risk factors for default from multidrug-resistant tuberculosis treatment in rural South Africa: a retrospective cohort study. PLoS One. 2013;8(12):e83480.

41. Kliiman K. Highly drug-resistant tuberculosis in Estonia: risk factors and predictors of poor treatment outcome; 2010.

42. Kliiman K, Altraja A. Predictors of poor treatment outcome in multi-and extensively drug-resistant pulmonary TB. Eur Respir J. 2009;33(5):1085-94.

43. Kulkarni P, Akarte S, Mankeshwar R, Bhawalkar J, Banerjee A, Kulkarni A. Non. Adherence of new pulmonary tuberculosis patients to anti. Tuberculosis treatment. Ann Med Health Sci Res. 2013:3(1):67-74.

44. Laprawat S, Peltzer K, Pansila W, Tansakul C. Alcohol use disorder and tuberculosis treatment: A longitudinal mixed-method study in Thailand. S Afr J Psychiatry. 2017;2:25-30.

45. Louw J, Peltzer K, Naidoo P, Matseke G, Mchunu G, Tutshana B. Quality of life among tuberculosis (TB), TB retreatment and/or TB-HIV co-infected primary public health care patients in three districts in South Africa. Health Qual Life Outcomes. 2012;10(1):77.

46. Louw JS, Mabaso M, Peltzer K. Change in health-related quality of life among pulmonary tuberculosis patients at primary health care settings in South Africa: a prospective cohort study. PLoS One. 2016;11(5):e0151892.

47. Miller AC, Nelson AK, Livchits V, Greenfield SF, Yanova G, Yanov S, et al. Understanding HIV risk behavior among tuberculosis patients with alcohol use disorders in Tomsk, Russian Federation. PloS one. 2016;11(2):e0148910.

48. Peltzer K. Conjoint alcohol and tobacco use among tuberculosis patients in public primary healthcare in South Africa. S Afr J Psychiatry. 2014;20(1):21-6.

49. Peltzer K, Louw J. Prevalence and associated factors of tuberculosis treatment outcome among hazardous or harmful alcohol users in public primary health care in South Africa. Afr Health Sci. 2014;14(1):157-66.

50. Tesfahuneygn $\mathrm{G}$, Medhin $\mathrm{G}$, Legesse M. Adherence to anti-tuberculosis treatment and treatment outcomes among tuberculosis patients in Alamata District, Northeast Ethiopia. BMC Res Notes. 2015:8(1):503.

51. Tesfaye M, Adorjan K, Krahl W, Tesfaye E, Yitayih Y, Strobl R, et al. Khat and alcohol use disorders predict poorer adherence to anti-tuberculosis medications in Southwest Ethiopia: a prospective cohort study. 2019.

52. Thomas BE, Thiruvengadam K, Kadam D, Ovung S, Sivakumar S, Bala Yogendra Shivakumar SV, et al. Smoking, alcohol use disorder, and tuberculosis treatment outcomes: A dual co-morbidity burden that cannot be ignored. PLoS One. 2019;14(7):e0220507.

53. Tola HH, Shojaeizadeh D, Garmaroudi G, Tol A, Yekaninejad MS, Ejeta LT, et al. Psychological distress and its effect on tuberculosis treatment outcomes in Ethiopia. Glob Health Action. 2015;8(1):29019.

54. Thummar PD, Rupani MP. Prevalence, and predictors of hazardous alcohol use among tuberculosis patients: the need for a policy on joint tuberculosis-alcohol collaborative activities in India. Alcohol. 2020

55. Mathew TA, Yanov SA, Mazitov R, Mishustin SP, Strelis AK, Yanova GV, et al. Integration of alcohol use disorders identification and management in the tuberculosis programme in Tomsk Oblast, Russia. Eur J Public Health. 2009; 19(1):16-8.

56. Kliiman K. Highly drug-resistent tuberculosis in Estonia: risk factors and predictors of poor treatment outcome:

57. Duko B, Ayalew M, Ayano G. The prevalence of alcohol use disorders among people living with HIV/AIDS: a systematic review and meta-analysis. Subst Abuse Treat Prev Policy. 2019;14(1):52

58. Necho M, Belete A, Getachew Y. Prevalence and factors associated with alcohol use disorder among people living with HIV/AIDS in Africa: a systematic review and meta-analysis; 2020.

59. Grant BF, Goldstein RB, Saha TD, Chou SP, Jung J, Zhang H, et al. Epidemiology of DSM-5 alcohol use disorder: results from the National Epidemiologic Survey on alcohol and related conditions III. JAMA Psychiatry. 2015;72(8):757-66

60. Manthey J, Gual A, Jakubczyk A, Pieper L, Probst C, Struzzo P, et al. Alcohol use disorders in Europe: a comparison of general population and primary health care prevalence rates. J Subst Abus. 2016:21(5):478-84.

61. Mewton L, Teesson M, Slade T, Grove R. The epidemiology of DSM-IV alcohol use disorders amongst young adults in the Australian population. Alcohol Alcohol. 2011;46(2):185-91. 
62. Ayano G, Yohannis K, Abraha M, Duko B. The epidemiology of alcohol consumption in Ethiopia: a systematic review and meta-analysis. Subst Abuse Treat Prev Policy. 2019;14(1):26.

63. Plant ML. The role of alcohol in women's lives: a review of issues and responses. J Subst Abus. 2008;13(3):155-91.

64. Brenner Darren R, Haig Tiffany R, Poirier Abbey E, Akawung Alianu FCM Robson PJ. Alcohol consumption and low-risk drinking guidelines among adults: a cross-sectional analysis from Alberta's Tomorrow Project. Health Promot Chronic Dis Prev Can. 2017;37(12):413.

65. Francis JM, Grosskurth H, Changalucha J, Kapiga SH, Weiss HA. Systematic review and meta-analysis: prevalence of alcohol use among young people in eastern a Africa. Tropical Med Int Health. 2014;19(4):476-88.

66. Ely M, Hardy R, Longford NT, Wadsworth ME. Gender differences in the relationship between alcohol consumption and drink problems are largely accounted for by body water. Alcohol Alcohol. 1999:34(6):894-902.

67. Urban NB, Kegeles LS, Slifstein M, Xu X, Martinez D, Sakr E, et al. Sex differences in striatal dopamine release in young adults after oral alcohol challenge: a positron emission tomography imaging study with [11C] raclopride. Biol Psychiatry. 2010;68(8):689-96.

68. Glantz MD, Medina-Mora ME, Petukhova M, Andrade LH, Anthony JC, De Girolamo G, et al. Alcohol abuse in developed and developing countries in the world mental health surveys: socially defined consequences or psychiatric disorder? Am J Addict. 2014;23(2):145-55.

69. Grant BF, Dawson DA. Age at onset of alcohol use and its association with DSM-IV alcohol abuse and dependence: results from the National Longitudinal Alcohol Epidemiologic Survey. J Subst Abus. 1997:9:103-10.

\section{Publisher's Note}

Springer Nature remains neutral with regard to jurisdictional claims in published maps and institutional affiliations.

Ready to submit your research? Choose BMC and benefit from:

- fast, convenient online submission

- thorough peer review by experienced researchers in your field

- rapid publication on acceptance

- support for research data, including large and complex data types

- gold Open Access which fosters wider collaboration and increased citations

- maximum visibility for your research: over $100 \mathrm{M}$ website views per year

At $\mathrm{BMC}$, research is always in progress.

Learn more biomedcentral.com/submissions 